Cronfa - Swansea University Open Access Repository

This is an author produced version of a paper published in :

Journal of Pragmatics

Cronfa URL for this paper:

http://cronfa.swan.ac.uk/Record/cronfa27596

http://dx.doi.org/10.1016/j.pragma.2016.04.010

This article is brought to you by Swansea University. Any person downloading material is agreeing to abide by the terms of the repository licence. Authors are personally responsible for adhering to publisher restrictions or conditions. When uploading content they are required to comply with their publisher agreement and the SHERPA RoMEO database to judge whether or not it is copyright safe to add this version of the paper to this repository. http://www.swansea.ac.uk/iss/researchsupport/cronfa-support/ 


\section{Quotatives. New Trends and Sociolinguistic Implications.}

Isabelle Buchstaller, Wiley Blackwell, Malden, MA, 2014, 306 pages, ISBN: 978-0470-65718-8, GBP 79.50 / EUR 107.40 (hardcover)

The rise of quotative be like in American English and other English varieties is one of the most intensely studied topics in quantitative sociolinguistics in the past twenty years or so. Particularly interesting from a pragmatics perspective is the unique ability of this quotative to blur the boundary between representation of plausibly uttered speech (bona fide 'reported speech') and representation of a range of other discourse-pragmatic functions, such as unuttered thoughts or internal reactions, and non-verbal reactions, including non-lexicalized sounds and gestures. In fact, in its non-referential forms (e.g., it's like) be like can even blur the boundaries between quotative and discourse marker (or filler) functions. With the growing number of studies documenting the global spread of be like, sociolinguists have been debating the causes and mechanisms of the rapid diffusion of this quotative, and the indeterminacy of its discourse-pragmatic function has been claimed to be a key factor in this extraordinary phenomenon (Buchstaller, 2011). In the first monograph on this popular topic, Buchstaller surveys the extensive body of variationist research on innovative English quotatives (be like, go, be all), extends some of her own previous analyses of quotative use and attitudes surrounding them, and weighs in on current debates. The book comprises six major chapters, each with its own reference list and extensive endnotes. The first two chapters are introductory, dealing with theoretical aspects of quotation and quotative frames. Chapter 1 examines textual, pragmatic, and typological properties of quotatives, with the goal of explaining why quotation has become so productive in the past twenty years, though the assumption that quotation has never been as productive in the history of English remains unsupported. A noteworthy contribution of the chapter is Buchstaller's proposal of a "constructional template" for innovative quotatives - NOUN PHRASE + COPULA + (DISCOURSE MARKER) + QUOTE (p. 17) - which aims to generalize and maximally reduce variation within innovative quotative frames. Another valuable feature of this chapter is that it provides a cross-linguistic perspective, showing that a striking majority of 'new' quotatives, in typologically-related as well as unrelated languages, are markers of approximation or comparison.

Chapter 2 is devoted to the definition of quotation, and ultimately aims to justify the operationalization of quotation adopted in previous (variationist) research, and in analyses in ensuing chapters. The chapter first surveys work on direct quotation from different theoretical paradigms - cognitive linguistics, variationist sociolinguistics, literary stylistics, syntax, semantics, pragmatics, etc. The second part of the chapter reproduces Buchstaller's (2011) comparison of a quantitative analysis conducted by coding quotations following a conservative definition with an analysis based on a maximally-inclusive definition. Here Buchstaller draws on discourse and conversation analytic perspectives which have regarded reported speech as a marker of speaker stance in interaction (e.g., Clift, 2006) to justify inclusion of complement clauses governed by stance verbs (e.g., I think, I guess). 
But demonstrating that reported speech can function as "interactional evidential" - as Clift does - is not equivalent to claiming that stance markers introduce quotations, which is what Buchstaller effectively suggests, albeit for illustrative purposes. As the majority of the examples used to illustrate this maximally-inclusive approach are simply complement clauses (with zero complementizer) governed by a stance marker and no deictic shifts (e.g., I suppose [that] there is such a thing as a class system you know, in (34), p. 69), the experiment is not particularly effective. Indeed, instances which do not include a deictic or prosodic shift to mark a frame shift are not typically regarded as direct quotations, even in studies focusing on reported mental states (e.g., Vásquez and Urzúa, 2009). Despite this perplexing analysis, with its thorough review of semantic, syntactic, and cognitive accounts of quotation, this chapter, coupled with Chapter 1, has much to offer to readers interested in theoretical and qualitative aspects of quotation.

With Chapter 3 the book turns to its main focus, namely quantitative analyses of quotative use and attitudes. Chapter 3 first surveys research findings on quotative use in association with social and linguistic factors, namely speaker sex, age, tense of the quotative, grammatical person of the subject, "content of the quote" (p. 102) i.e., whether the quotation reproduces speech that was plausibly uttered, or whether instead it reproduces speaker's thoughts - and "mimetic enactment", i.e., whether (or not) the quotation is accompanied by expressive sounds, or gesture. It then turns to a comparison of quotative use among teenagers and university students in Northern England (Newcastle) and California in the mid-2000s. Chapter 4 extends Buchstaller's (2011) diachronic analysis of quotative use in Tyneside English, based on the Diachronic Corpus of Tyneside English (DECTE). Chapter 5 explores attitudes and ideologies surrounding quotative be like, while Chapter 6 revisits key debates discussed in the book, including the role of the media in the global spread of be like, and whether the "localized adaptation" of be like in different English varieties suggests that its diffusion in those varieties should be treated as "the same' phenomenon" or as parallel but different phenomena (p. 249).

The quantitative analyses in the two central chapters feature noteworthy methodological choices. In Chapter 3, Buchstaller turns the comparison of quotative use in Newcastle and California youth speech into a methodological case study, showing how two different methods of calculating proportional use can lead to potentially conflicting analyses of quotative use. One method involves calculating proportional use out of all occurrences of the quotative (e.g., percentage of be like with first person subjects out of all occurrences of be like). In this case the variant is the denominator. The other method - the variationist method - involves calculating proportional use out of all quotatives in that particular linguistic context (e.g., first person subjects), thus using the variable as denominator. Buchstaller justifies her choice to present calculations (for all variables) with both methods with the fact that "sociolinguistic data tends not to be normally distributed" and is "skewed along several dimensions" (p. 120). In the closing synthesis of the relationship between quotative use in youth talk, gender, and linguistic variables, however, Buchstaller draws from the calculations following the variationist method, to align with "majority trends and tendencies" (p. 135). 
The swinging between calculation methods continues in Chapter 4, which extends Buchstaller's (2011) diachronic analysis of quotative use in Tyneside English by comparing quotatives in youth and older speakers' speech. Here, again dealing with "multiple skews in the data" (p. 160), Buchstaller shows how the two calculation methods lead to conflicting pictures of quotative use with grammatical person by Tyneside youth (Tables 4.6a, 4.6b, 4.7a, and 4.7b). In this case, though, it is the calculation with variant as denominator (non-variationist method) that would support Tagliamonte and D'Arcy's (2004) finding that in the mid-1990s, in Canadian English, be like was favored with first person contexts (e.g., I'm like) rather than third person contexts (e.g., she's like) - a finding, based on variationist methodology, which had led Tagliamonte and D'Arcy to reject the hypothesis that quotative be like was expanding to third person contexts. Accordingly, given that the variationist calculation method appears to be "vulnerable to both intersecting skews", namely "the numerical imbalance amongst the quotative variants as well as uneven rate of occurrence across linguistic contexts" (p. 160), Buchstaller presents the remaining analyses based on calculation of proportional use out of total use of the quotative (i.e., variant as denominator or "non-variationist method"), offering tables with alternative calculations (i.e., variable as denominator) in an appendix.

Buchstaller's choice to present analyses based on two calculation methods in Chapters 3 and 4 is useful, but the rationale for doing so is flawed. First, there is nothing extraordinary about the "numerical skews" in these particular datasets: naturally-occurring language data - not just sociolinguistic data - is typically not normally distributed. Nor should we expect calculation methods reflecting different research designs to produce matching proportional distributions. Rather, percentages based on small raw numbers can be misleading, and should be treated cautiously. Buchstaller makes passing comments about small raw numbers for quotatives go and be like among older Tyneside English speakers in the 1990s (Table 4.6a), but overall this problem is not adequately addressed. For example an extensive discussion of use of be like and go by older speakers in the 1990s and 2000 s to report speech versus thought is based on eight and four occurrences respectively of these quotatives (Chapter 4 ; Tables $4.22,4.24$ ). This raises questions, amongst others, about dispersion of the tokens: were those tokens produced by one or more speakers?

A more serious problem concerns the representativeness of the samples in some of the analyses. The cross-variety comparison (US vs. UK) of quotative use by gender (Chapter 3 ) is based on datasets comprising ten speakers, namely five speakers for each sex in each variety (Tables 3.9a, 3.9b, 3.10a, 3.10b). It is surprising that based on such sample size (and a non-significant statistical test, Table 3.10a), Buchstaller can claim that "evidently, the gender difference as regards like usage has not neutralized across time in the two localities" (p. 124).

An interesting twist is Buchstaller's choice to depart from established variationist methodology for the statistical analyses, by not using VARBRUL/GOLDVARB, the statistical package for multiple logistic regression, modeled on the concept of "variable rule", and designed to evaluate the relationship between multiple factors and a binary linguistic choice. Buchstaller (citing Johnson, 
2009) explains that VARBRUL is inappropriate for analyses of variance that include four or five variants, and warns that "collapsing the dependent variable (i.e., collapsing the contrast to one that opposes be like against all other quotatives) - as some previous research projects have done - would preclude investigating the restructuring amongst the multiple competitor variants within the system of quotation" (p. 123; see also pp. 160-161). Given the seemingly unwary use of VARBRUL in previous variationist quotative studies, this is only timely. However, this point needed to be taken further to become truly useful. That is, given that discussions of trends in previous research and comparisons with analyses in the book are effectively restricted to variationist studies, which have typically used VARBRUL, one would have expected a critical appraisal of previous VARBRUL-based findings on quotative use. One of the limitations of VARBRUL/GOLDVARB, for example, is that it tends to overestimate the effect of social factors (e.g., age, sex) (Johnson, 2009; p. 363). Thus, readers might wonder if previous conclusions that the sex effect has not neutralized (Tagliamonte and D'Arcy, 2004) might have been misled by VARBRUL's overestimation of the sex factor. This is not something that readers can necessarily verify independently, especially since variationist studies tend to not report all frequency data (see, e.g., Tagliamonte and D'Arcy, 2004; Durham et al., 2012).

There are also a few perplexing methodological choices concerning coding of particular quotative frames. One concerns the frame IT'S LIKE, a notoriously problematic frame due to the indeterminacy of its discourse-pragmatic function, that is whether it introduces direct quotation, or whether instead it functions simply as discourse marker. Buchstaller laments that only Durham et al. (2012) (cited as Haddican et al. 2012) and Buchstaller and D'Arcy (2009) exclude it (p. 105), while "other research remains silent" (p. 105) about inclusion criteria. Barbieri (2005) actually excludes it and discusses it at length (pp. 12-13). Crucially, Barbieri shows that when used as a quotative, it's like does not introduce speech, but rather a representation of unuttered thoughts or internal reactions. Buchstaller includes quotative it's like in her analyses, usefully separating it from the counts for third person. Surprisingly, however, in the analysis of the discourse pragmatic-function, it's like with "mimetic effect" is classified as direct speech. This contributes to inflate the counts for direct speech, and compromises comparability with previous studies.

Another one concerns non-conventional quotatives, that is quotative frames that somehow do not fit the binary distinction present / past tense (e.g., progressive and perfect aspect forms, conditionals). Typically neglected in quotative studies, these would have merited systematic discussion in a monograph - particularly in Chapter 2, which focuses on the operationalization of quotation. Analyses of quotative use with tense would have benefited from explanations of inclusion criteria. For example, it is unclear what the "other' tenses and aspects" (p. 164) are, given that English has two tenses. Were quotatives in perfect aspect classified according to tense (present or past) or as "other"?

Particularly interesting is the analysis of quotatives in association with "genre" (Chapter 4). The term "genre" is somewhat misleading as it refers to the distinction between narrative and non-narrative sequences (in the Labovian sense) - thus to "discourse modes" (Georgakopoulou and Goutsos, 2004) - within the sociolinguistic 
interview, rather than to distinct communicative events or situated varieties. Analyses here reveal that regardless of social factors, quotative say is favored in non-narrative sequences. This points to the role of communicative function (hence register) in constraining quotative choice.

This finding should be interpreted against the backdrop of the complexity and multifunctionality of direct quotation, and the ensuing variability of quotative frames, which is only partially explained by social characteristics of the speaker and internal linguistic factors. Quotative use is also affected by discourse mode and situation of use (register). In variationist research however quotation has been studied based exclusively on language samples produced in tightly controlled speech events, namely the sociolinguistic interview. But quotatives, like most lexico-grammatical features, vary according to situation of use (Barbieri, 2005). This fact, coupled with the lack of functional equivalence between certain quotatives (e.g., it's like vs it says; progressive forms of say, think etc.) questions the suitability of the variationist model for discourse-pragmatic variables. The complete disregard for the implications of the theoretical complexity of quotation for variation of quotatives across registers of spoken interaction is, in my view, the main theoretical limitation of the book.

When it comes to the controversial issue of the role of the media in the diffusion of be like, Buchstaller is cautious and remains confined to the conservative position of sociolinguists who dismiss the role of the media for lack of evidence. Buchstaller notes that a few American movies continue to propagate the Valley Girl trope. One wonders though if a few salient occurrences in a handful of relatively unknown movies can outweigh the likely far more numerous "neutral" occurrences in a wide range of spoken media, such as sitcoms and informal entertainment networks, to which speakers are continuously exposed (or were, before digital media became pervasive). If anything, such isolated cases might explain why very few informants in Buchstaller's attitudinal study (Chapter 5) associated be like with Valley Girl talk. Likewise, one study of a bilingual community (Dion and Poplack, 2007; conference paper cited in Buchstaller) seems insufficient to rule out the potential role of the broadcast media in mediating the spread of informal or colloquial constructions beyond local, colloquial contexts, possibly through a process which Fitzmaurice (2000) has likened to dialect leveling.

The limitations I have discussed here should however not detract from the many contributions of the volume. Buchstaller's monograph offers the most extensive review of variationist research on quotatives in English varieties, and a thorough account of quotative use in California youth and across generations of Tyneside English. As such, it will be appealing to a wide range of scholars of language change, particularly those interested in discourse-pragmatic features, and will be invaluable to those new to quotatives. Readers will appreciate the tables summarizing previous empirical studies (Chapter 3 ), the thorough endnotes, and the extensive quantitative analyses. The commendable strive to thoroughness that characterizes the book sometimes incurs in repetitiveness though (e.g., both Chapters 1 and 3 survey the attestation of innovative quotatives). Similarly, Buchstaller might have been more selective with tables and figures (nearly 200 total, 
and over 40 in some chapters). The risk with several alternative, parallel analyses is overwhelming the reader, who may lose "the story".

\section{REFERENCES:}

Barbieri, Federica, 2005. Quotative use in American English: A corpus-based, crossregister comparison. Journal of English Linguistics 33(3), 222-256.

Buchstaller, Isabelle, 2011. Quotations across the generations: A multivariate analysis of speech and thought introducers across 5 decades of Tyneside speech. Corpus Linguistics and Linguistic Theory 7(1), 59-92.

Clift, Rebecca, 2006. Indexing stance: Reported speech as an interactional evidential. Journal of Sociolinguistics 10(5), 569-595.

Durham, Mercedes, Haddican, Bill, Zweig, Eytan, Johnson, Daniel Ezra, Baker, Zipporah, Cockeram, David, Danks, Esther, Tyler, Louise, 2012. Constant linguistic effects in the diffusion of be like. Journal of English Linguistics 40(4), 316-337.

Fitzmaurice, Susan, 2000. The great leveler: The role of the spoken media in stylistic shift from the colloquial to the conventional. American Speech 75(1), 54-68.

Georgakopoulou, Alexandra, Goutsos, Dionisis, 2004. Discourse Analysis. An Introduction. Edinburgh University Press, Edinburgh.

Johnson, Daniel Ezra, 2009. Getting off the GoldVarb standard: Introducing Rbrul for mixed-effects variable rule analysis. Language and Linguistics Compass 3(1), 359-383.

Tagliamonte, Sali, D'Arcy, Alexandra, 2004. He's like, she's like: The quotative system in Canadian youth. Journal of Sociolinguistics 8(4), 493-514.

Vásquez, Camilla, Urzúa, Alfredo, 2009. Reported speech and reported mental states in mentoring meetings: Exploring novice teacher identities. Research on Language and Social Interaction 42(1), 1-19. 